\title{
POLÍTICAS EDUCACIONAIS DE FORMAÇÃO CONTINUADA E O PROGRAMA DE DESENVOLVIMENTO PROFISSIONAL DE MINAS \\ GERAIS
}

\section{EDUCATIONAL POLICIES FOR CONTINUED FORMATION AND THE PROGRAM OF PROFESSIONAL DEVELOPMENT OF THE STATE OF MINAS GERAIS}

\author{
Jacqueline de Sousa Batista Figueiredo * \\ Jairo de Araujo Lopes ${ }^{* *}$
}

\section{Resumo}

Este trabalho tem por objetivo analisar a implantação de uma política pública mineira do Projeto Escolas-Referência com o Programa de Desenvolvimento Profissional de Educadores - PDP - desenvolvido na jurisdição da Superintendência Regional de Ensino de Poços de Caldas-MG no contexto das políticas públicas, nos âmbitos federal e estadual, de capacitação continuada. O Programa tem a pretensão de inserir o professor como construtor e reconstrutor de seu percurso formativo e profissional por meio do desenvolvimento de atividades, do acompanhamento e suporte pedagógico para a implantação das novas propostas curriculares - a conjectura do Currículo Básico Comum. Mediante análise bibliográfica e documental, e de depoimento de quatro docentes participantes ativos do processo, refletiu-se, a partir de referências teóricas referentes a políticas públicas, sobre inquietações decorrentes da implantação da nova proposta no meio escolar, buscando conhecer os pontos que representam avanços e obstáculos do PDP.

Palavras-chave: Políticas públicas, formação continuada, currículo escolar.

\begin{abstract}
The aim of this task is to analyse the introduction of a public policy from a project called "Good Reference Schools" with the Professional Development Program for Educators that was made by "Superintendência Regional de Ensino" in Poços de Caldas, Minas Gerais. Preparing teachers in both Federal and State scopes. The program intends to include teachers as builders in the professional development by activities with pedagogical support to introduce new proposals for a good academic

\footnotetext{
* Mestranda PUC-Campinas: jacqueline figueiredo@yahoo.com.br

** PUC-Campinas - Prof. Programa de Mestrado em Educação: jairo@puc-campinas.edu.br
} 


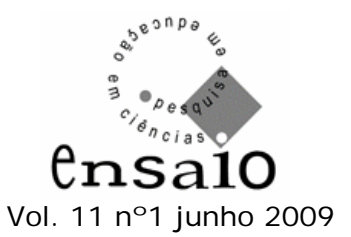

record according to the one they have to follow called "Currículo Básico Comum". Based on important facts four teachers have reported and some documents analysis, we conclude that there are a few doubts about introducing the new proposal at schools that have to be solved.

Key words: Public policy, continued formation, academic record.

\section{INTRODUÇÃO}

A sociedade vem sofrendo mudanças aceleradas em suas estruturas e formas de organização. Essas rápidas mudanças provocam transformações na vida institucional relacionadas, principalmente, à qualidade de ensino. Esse fenômeno tem acelerado o desenvolvimento de políticas públicas, fundamentadas nas reformas em curso no Brasil definindo novo perfil de educadores para as exigências de uma nova formação escolar renovada.

Atendendo às normas da Constituição Federal, da Lei das Diretrizes e Bases da Educação Nacional e do Plano Nacional de Educação (Lei 10.172 de 2001), o Estado de Minas Gerais vem desenvolvendo, a partir de 2003, políticas públicas para a educação, dando ênfase à educação continuada como instrumento fundamental de transformação do quadro educacional. Entre essas medidas podemos destacar o Projeto Escolas-Referência, visando ações que busquem a reconstrução da excelência na rede pública por meio do desenvolvimento pedagógico e institucional escolar, do desenvolvimento da gestão educacional e dos educadores, e da solidariedade e da cultura do trabalho colaborativo.

Diante dessas diretrizes e da inquietação que uma nova proposta ocasiona no meio escolar, este trabalho procura analisar o Programa de Desenvolvimento Profissional de Educadores do Estado de Minas Gerais no contexto das políticas públicas de capacitação continuada nos âmbitos federal e estadual. Tem por objetivo identificar pontos que possam significar avanços ou configurar retrocessos do Programa de Desenvolvimento Profissional - PDP - no período de 2003 a 2006, frente a referenciais teóricos e a políticas educacionais. Com esse intuito, fez-se uso não só da pesquisa bibliográfica e documental, como de depoimentos de professores que participaram do processo. 


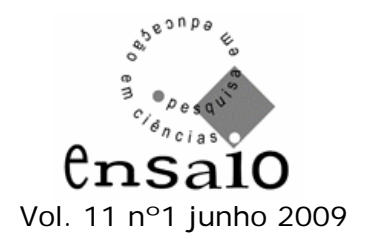

\section{REFLEXÕES SOBRE CONTEXTO GLOBAL}

No Brasil, as políticas educacionais públicas estão inseridas numa onda de acordos internacionais concretizados em diversos eventos, dentre eles, a Conferência Mundial de Educação para Todos, realizada em Jontien, Tailândia (1990); a Conferência de Nova Delhi (1993) e as reuniões relacionadas à Educação na América Latina e Caribe, a exemplo da Conferência de Kingston, realizada na Jamaica em 1996.

Estão presentes, no país, três agências internacionais voltadas para o desenvolvimento de projetos na área da educação. A primeira é o Fundo das Nações Unidas para a Infância (Unicef). A segunda é a Organização das Nações Unidas para a Educação, a Ciência e a Cultura (UNESCO). A terceira é constituída pelo o Banco Mundial (BIRD) e pelo Banco Interamericano de Desenvolvimento (BID) que tem exercido papel relevante, definindo indicadores de qualidade da educação com o intuito de melhorar a sua competitividade no mercado internacional. No item referente à melhoria da qualidade (e da eficácia) da educação como eixo da reforma educativa, o Banco Mundial prioriza três frentes (ALTMANN, 2002): o aumento do tempo de instrução; a melhoria do livro didático; a capacitação em serviço dos educadores preconizando a educação à distância.

Apple (2000), Coraggio (1996), Torres (1996), vinculados a uma visão crítica, têm denunciado essa concepção utilitarista da educação, adequando-a ao mercado de trabalho. Alguns fatos fundamentais foram analisados por Torres (1996) como: a visível ausência de professores na determinação de projetos para a reforma educacional; a falta de preparação do professor em fase anterior à implantação de reformas educacionais; propostas preparadas por autores estrangeiros que não conhecem bem a realidade educacional do país; elaboração do currículo atrelada ao mercado; insuficiências de recursos na elaboração de propostas para a educação básica e desatenção à formação superior; avaliação do ensino direcionada ao atendimento da relação custo-benefício. Para a autora, a educação, nesse sentido, torna-se um investimento não na direção de proporcionar 


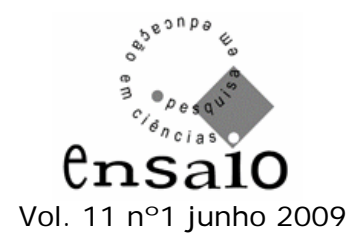

avanço na qualidade de ensino, mas como perspectiva de lucro e restituição econômica para o mercado.

Fusari e Rios (1995) assinalam que a política de formação em serviço deve pautar por alguns pressupostos indispensáveis à democratização da educação escolar brasileira, como os apontados por Torres, e acrescentam que os problemas reais devem ser concebidos como ponto inicial e de desfecho do processo, garantindo-se a reflexão com fundamentação teórica, explicitando caminhos para uma atuação competente.

O Banco Mundial ressalta que o problema da educação brasileira é a baixa qualidade do ensino, o que provoca elevados índices de evasão e repetência. Para melhorá-la, propõe a sua eficácia através dos fatores: melhoria da capacidade de aprendizagem do aluno; redução das altas taxas de repetência; aumento das despesas por aluno (TOMMASI, 1996). O Banco considera que a insuficiência quantitativa e qualitativa de livros didáticos e materiais pedagógicos, a ineficácia da prática pedagógica e a ineficiente capacidade de gestão contribuem para aumentar a baixa qualidade na educação. São fatores enunciados em 1992 para o estabelecimento de medidas prioritárias para seus empreendimentos no Brasil. As medidas não incluem, entretanto, ações relativas à motivação dos professores e ao aumento de suas oportunidades profissionais. (TOMMASI, 1996)

O Banco Mundial tem apoiado os projetos desenvolvidos pelas secretarias estaduais que considera inovadores para a melhoria da qualidade na educação, ou seja, projetos em que o professor é “o protagonista da modernização, um sujeito a ser profissionalizado, exigindo-lhe um 'saber fazer' que supere o descompasso entre sua prática de ensino e a vida.” (PACHECO, MORAES e EVANGELISTA, 2001, p. 188). Isso nos leva a interrogar a respeito de sua qualificação. Será que o professor nunca foi um profissional e, para tanto, necessita de uma reprofissionalização? É fundamental que o docente desenvolva competências; mas por que as políticas de formação privilegiam as competências demandadas pelo mercado? Isso não acarretaria uma expropriação do conhecimento? E qual é, para o Banco Mundial, o significado de projetos inovadores? 


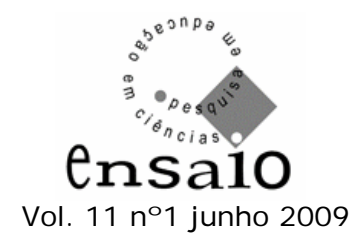

Em relação às políticas de formação continuada, a Secretaria de Estado de Educação de Minas Gerais (SEEMG) define os cursos e contrata agentes formadores para esse fim.

Segundo Lima (2001), a SEEMG tem adotado, como metodologia de formação continuada, a parceria com grupos de especialistas em educação que se responsabilizam pela prescrição, implementação e gestão de recursos das políticas públicas. Salienta que os principais interessados, ou seja, os educadores são apenas comunicados, convidados, senão convocados para participarem dos projetos de formação continuada. Os anseios, os conflitos, a realidade escolar, os saberes docentes não são considerados na capacitação por ser ela originada e definida externamente.

\section{O PROGRAMA DE DESENVOLVIMENTO PROFISSIONAL DE EDUCADORES - PDP}

Tendo em vista a reconstrução da excelência na escola pública, a SEEMG criou o projeto Escolas-Referência que teve, como primeira meta, em 2003, uma etapa piloto com a participação de três escolas: o Instituto de Educação de Minas Gerais - Belo Horizonte; a Escola Estadual Governador Milton Campos - Belo Horizonte; a Escola Estadual Professor Plínio Ribeiro - Montes Claros. Sua segunda meta foi implantar, em 2004, o Projeto Escolas-Referência nas escolas estaduais que vinham desenvolvendo projetos bem-sucedidos na solução de seus problemas educacionais. Almeja-se que essas escolas difundam uma mudança de práticas de ensino por meio da interação com outras escolas tornando-se referência para uma educação pública de qualidade. Em 2005, teve como terceira meta a implantação da segunda etapa, incluindo mais 200 escolas e, em 2006, a quarta etapa, acrescentando outras 200 escolas como Escolas-Referência.

O Projeto Escolas-Referência tem como desafio o desenvolvimento de redes de interações. As escolas que participam desse projeto têm suas atividades e projetos elaborados dentro de um sistema de comunicação para divulgação. Essa rede tem por objetivo incentivar a troca de experiências e a busca de soluções conjuntas. (SEEMG, Projeto Escolas-Referência, 2004) 


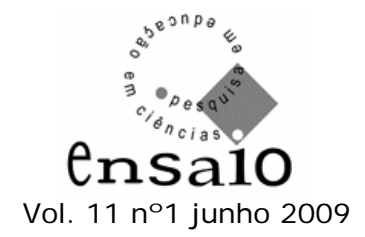

Para participar do projeto, as escolas de ensino fundamental e médio, ou só de ensino fundamental, foram submetidas aos seguintes critérios: I. Localização em municípios com mais de 30.000 habitantes; II. O ensino médio ter mais de 1.000 alunos; III. Possuírem experiência significativa na área pedagógica ou de gestão escolar. (SEEMG, 2004)

Um eixo desse projeto é denominado Programa de Desenvolvimento Profissional de Educadores (PDP), mantido pela Secretaria, com a participação de consultores, a maior parte ligada à Universidade Federal de Minas Gerais. Começou a ser implantado em 2004 com o objetivo de promover o desenvolvimento profissional dos docentes em exercício nas escolas estaduais e valorizá-los. O PDP tem como unidade básica o Grupo de Desenvolvimento Profissional de Professores (GDP), uma equipe operativa e estratégica do programa desenvolvido.

Foram instituídos 800 GDP, distribuídos por 200 escolas. Cada GDP é constituído por, pelo menos, 14 professores de áreas distintas e/ou especialistas de educação efetivos ou designados, em exercício na escola. Os membros participantes escolhem um coordenador para o desenvolvimento dos encargos decorrentes do programa e interação direta com o orientador do GDP, por meio de encontros presenciais periódicos e através da internet objetivando a comunicação e o desenvolvimento dos trabalhos. O orientador de GDP é um profissional qualificado, indicado pela coordenação central do PDP, responsável pelo planejamento, acompanhamento, execução, controle e avaliação do projeto.

Para a SEEMG (2004), “o GDP é a célula básica do PDP, em função da qual se articulam todos os outros elementos. Sua perspectiva é a de constituir-se em grupo operativo e estratégico do PDP” (p.6). Salienta que "saber trabalhar em pequenos grupos é essencial, pois, são eles que vão consolidar estratégias de ação coletiva no seio dos educadores pelo desenvolvimento de uma cultura de cooperação e compartilhamento”. (SEEMG, 2004, p. 15)

A maior parte das orientações dadas aos GDP, no decorrer do ano de 2004, dirigiu-se à construção do programa com o objetivo de elaborar as propostas curriculares a serem implantadas nas referidas escolas. Também foram previstos para os GDP: estudos e trabalhos individuais e em grupo; quatro encontros 


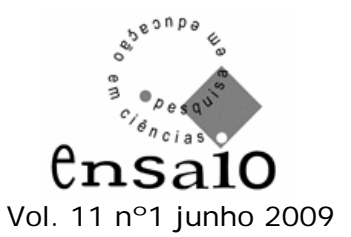

presenciais com os orientadores, realizados em Jaboticatubas, cidade pertencente ao pólo $\mathrm{BH}$; fóruns e bate-papos via web e a constituição das redes de trabalho. Para Mercado (1999), as redes de trabalho devem possibilitar “a rápida troca de mensagens entre pesquisadores, professores, alunos em qualquer parte do mundo.” (p. 117)

Os grupos assumiram o Plano Anual de Atividades contendo unidades temáticas com material de estudo e de orientação produzido e disponibilizado pela SEEMG. Esse plano anual compreende três temáticas:

a) Propostas curriculares - 100 horas - Os educadores devem estudar e discutir textos elaborados por profissionais da SEEMG e executar as tarefas solicitadas que são orientações de cada disciplina.

b) Avaliação da aprendizagem - 25 horas - Foi disponibilizado material de estudo e de discussão da metodologia de avaliação anual da aprendizagem dos alunos a ser adotada pela SEEMG.

c) Avaliação de desempenho - 25 horas - Foi disponibilizado material de estudo e discussão da metodologia de avaliação anual de desempenho individual dos profissionais da educação. (Manual: SEEMG Projeto Escolas-Referência e Manual do Coordenador, 2004)

\section{DESDOBRAMENTOS DO PROGRAMA DE DESENVOLVIMENTO PROFISSIONAL}

O PDP, em 2004, esteve voltado para a teorização e deliberação de um Currículo Básico Comum (CBC). A SEEMG entende como "básico" aquilo que o educando deve saber ao sair da escola, o que não significa que ele tenha que saber o mínimo. Este projeto, além de ações presenciais, definiu a escola como locus dessa formação. Nela foram realizados estudos e discussões entre os professores e seus coordenadores. Tal procedimento vem ao encontro da recomendação de Candau (2003): “o locus da formação a ser privilegiado é a própria escola; isto é, é preciso deslocar o locus da formação continuada de professores da universidade para a própria escola” (p. 55). 


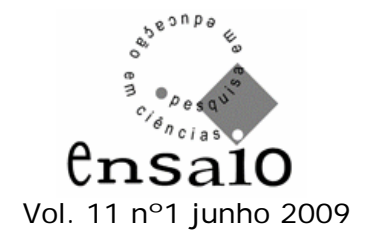

Uma equipe de consultores ficou encarregada de elaborar a versão inicial dos documentos para serem discutidos por professores e coordenadores de GDP, disponibilizados em um portal na Internet com as devidas orientações. Apenas os coordenadores de GDP possuíam código de usuário e senha para acesso a informações específicas e comentários dos orientadores. A SEEMG imprimiu cadernos - Guia de Estudos e Proposta Curricular - para orientar os GDP por meio de leituras que gerassem discussão e reflexão dos assuntos tratados nos textos. Em seguida, os GDP realizaram um consolidado a ser encaminhado, via site, pelo coordenador ao orientador para sua apreciação. O orientador, por sua vez, retornava questionamentos, sugestões, críticas e comentários relativos às atividades propostas. Estes estudos foram realizados nos meses de maio a dezembro de 2004.

A primeira fase do PDP, em 2004, correspondeu à discussão de conteúdos e à construção das propostas curriculares das disciplinas de Educação Básica para as Escolas-Referência da rede estadual. A segunda fase correspondeu à elaboração do projeto de Implantação das Propostas Curriculares com o objetivo de assegurar a continuidade do Programa, de avalizar as idéias dos professores contidas nas novas propostas para que fossem implantadas com sucesso, e para que os professores tivessem domínio metodológico do trabalho. Os GDP também receberam os módulos 1, 2, 3 e 4 do Manual de Orientação para elaboração de projetos de ensino, disponíveis também no site da SEEMG, com a finalidade de orientar a elaboração do Plano de Projeto de Ensino relativo à implantação das Novas Propostas Curriculares, contendo um resumo dos principais conceitos e métodos envolvidos no trabalho com este tipo de projeto.

Da Superintendência Regional de Ensino de Poços de Caldas, 4 (quatro) escolas participaram do Projeto Escolas-Referência perfazendo um total de onze (11) GDP. Cada GDP elaborou um portfólio com as respectivas atividades individuais e coletivas por disciplina, verificado pelos operadores regionais de GDP (técnicos da SRE) para certificação e retorno às escolas.

Os quatro encontros realizados na grande Belo Horizonte promoveram reuniões dos coordenadores com seus respectivos orientadores para que fossem sanadas as dificuldades encontradas e para novos encaminhamentos. Possibilitaram 


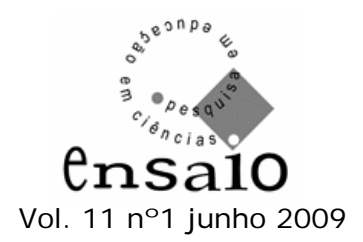

momentos de intercâmbio entre educadores de diversas localidades, configurandose em redes de trocas de experiências, assim como momentos de permuta de suas angústias, dilemas e reivindicações. Outro propósito dos encontros foi o de oportunizar aos coordenadores o debate de assuntos com orientadores de outras disciplinas, para que, ao retornarem às suas escolas, pudessem mediar discussões entre os componentes das diversas áreas.

Esse Plano Anual culminou com a elaboração de uma versão do Currículo Básico Comum - CBC - com a participação dos GDP de cada Escola-Referência, expressada na Proposta Curricular: Educação Básica.

Em 2005, o PDP esteve voltado para a instituição dos Conteúdos Básicos Comuns (CBC), que deveriam necessariamente ser trabalhados nas $5^{\text {a }}$ séries do ensino fundamental e na $1^{\text {a }}$ série do ensino médio da rede pública estadual. O CBC significou o produto final de estudos e discussões realizadas, durante 2004, pelos Grupos de Desenvolvimento Profissional (GDP) do Projeto Escolas-Referência.

A SEEMG, no uso de sua competência, estabeleceu, através da Resolução SEE No 666, de 07/04/2005, os Conteúdos Básicos Comuns a serem obrigatoriamente ensinados por todas as unidades estaduais de ensino. Os exemplares dos CBC foram distribuídos para as escolas estaduais que oferecem ensino fundamental e médio. Seus profissionais deveriam fazer uma avaliação do CBC e sugerir melhorias e modificações nos tópicos descritos no documento. A avaliação resultou na versão final do CBC introduzida em 2006.

A SEEMG, no decorrer de 2005, desenvolveu uma parte das atividades do PDP junto ao Centro de Referência Virtual do Professor (CRV), através de fóruns de debates das propostas curriculares de todas as disciplinas, com orientações, sugestões e indicações de bibliografias específicas. Outra parte foi desenvolvida especificamente com os GDP das Escolas-Referência no intuito de um aprofundamento da reflexão sobre as Novas Propostas Curriculares e da consolidação dos GDP como grupos operativos.

Para acompanhar e viabilizar o processo de implantação das propostas curriculares, cada grupo de GDP da SRE de Poços de Caldas, como também os outros grupos das demais SRE, escolheram 3 (três) professores integrantes de cada área de conhecimento (Ciências Humanas, Linguagens e seus Códigos, Ciências da 


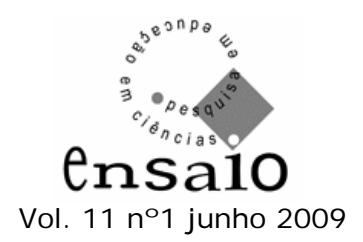

Natureza e Matemática), que participavam de GDP, como representantes de área, participantes de atividades específicas de acompanhamento da implantação das Propostas Curriculares, em Belo Horizonte, desenvolvendo aí atividades nos fóruns de debates das disciplinas.

Das Escolas-Referência da SRE de Poços de Caldas, 12 (doze) representantes foram escolhidos por consenso entre os 8 (oito) GDP constituídos em 2005.

Os representantes de área participaram de dois encontros em Belo Horizonte, recebendo orientações específicas sobre a implantação das Propostas Curriculares. O fórum de disciplina foi instituído como um suporte pedagógico para implantação das Novas Propostas Curriculares e Monitoramento e Avaliação do Processo.

O PDP, em 2006, esteve voltado para a garantia dos Planos Anuais dos GDP. Organizou suas ações a partir de três objetivos específicos: 1) orientar os GDP que optaram pelo acompanhamento e avaliação da implantação do CBC, em seus planos anuais de trabalho, no Acompanhamento e Avaliação da Implantação do Novo Plano Curricular (NPCEM) na $1^{\text {a }}$ série do Ensino Médio; 2) orientar os GDP que optaram por projetos de enriquecimento curricular, em seus planos anuais, no desenvolvimento de seus projetos; 3) ministrar 11 cursos em EAD. (SEEMG/ Coordenação Pedagógica do PDP)

A SEEMG reformulou, para 2006, os Planos Anuais de Trabalho dos GDP. Organizou um documento denominado “Novo Plano Curricular - Ensino Médio” que contextualiza a Resolução SEE Nº 753/06 de 06/01/2006.

O Novo Plano Curricular é apresentado como um "roteiro de estudo" para que professores integrantes do GDP levantem questões para serem refletidas no grupo. Teve caráter de um projeto piloto adotado nas Escolas-Referência e foi dividido em três partes: os desafios do ensino médio; os fundamentos, as diretrizes e os resultados esperados; as características da nova organização curricular.

No decorrer do ano de 2006, foram delegados às Escolas-Referência o acompanhamento e a avaliação de sua implantação, seguidos de relatórios enviados à SEE por meio eletrônico.

Toda essa descrição se fez necessária, pois acreditamos ser de grande valor a descrição do roteiro de estudo pelos professores integrantes de GDP. Isso nos 


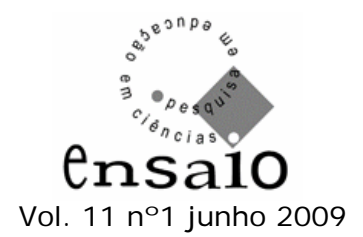

remete ao que Mizukami (2002, p.43) nos traz como alerta: “o que não for submetido à análise crítica no interior da escola não contribui para o desenvolvimento profissional nem para a autonomia; serve, quando serve, apenas para apagar os focos de incêndio que ameaçam emocional e profissionalmente o professor”.

Os GDP das Escolas-Referência que optaram por projetos de acompanhamento e avaliação do novo plano curricular, em seus planos anuais, desenvolveram ações para o acompanhamento da implantação do Novo Plano Curricular na $1^{\mathrm{a}}$ série do Ensino Médio, em apenas um turno, para todas as alternativas de Ensino Médio. As Escolas-Referência que possuem apenas o Ensino Fundamental desenvolveram projetos de Enriquecimento Curricular em seus Planos Anuais de Estudo.

Os procedimentos dos GDP foram semelhantes aos de 2005: participação em encontros, envio de tarefas aos orientadores pelo site e participação nos fóruns.

\section{O PDP NA ÓTICA DE AGENTES DO PROCESSO}

Em sintonia com esses estudos relativos à profissionalização docente, uma importante consideração a ser feita diz respeito aos estudos que compreendem o currículo e à política governamental do Estado de Minas Gerais para a educação, associados à formação continuada dos docentes mineiros. O CBC, para os professores, pode ser um meio de estudar, de pensar, de vivenciar, de questionar as propostas curriculares. A prescrição e a definição de um currículo deparam-se com histórias, valores, escolhas que permitem o desencadeamento de uma formação continuada. Ao se defrontar com o CBC, os GDP podem e devem discutir, divergir, pensar, e problematizar o que está sendo instituído para que não se torne, nas mãos de técnicos, mero instrumento de controle da criação do trabalho docente, mesmo que ele seja uma forma verticalizada para a organização do trabalho escolar. Trata-se de uma posição compartilhada por Leite (2005, p.134): “é preciso (...) reconhecer aos professores um conhecimento técnico e prático que se edifica sobre procedimentos de reflexão crítica que estruturam um conhecimento emancipatório”. 


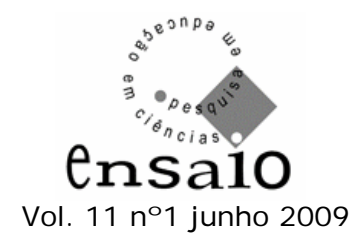

Para tanto, procedeu-se a um estudo com quatro professores participantes do programa, das disciplinas Biologia, Química, Geografia e Português, dos respectivos coordenadores de GDP e que atuam no Ensino Médio em Escola Estadual Referência, pertencentes à jurisdição da Superintendência Regional de Ensino de Poços de Caldas. A escolha deles seguiu critérios distintos: são sujeitos importantes para esclarecimento do tema em foco, são conhecedores das inquietações, aflições, ansiedades neles percebidas que impuseram necessidade de uma revisão teórica para repensarem os estudos sobre a sua própria prática educativa; estudaram as propostas e são capacitados pelo programa; têm acesso aos problemas da sala de aula e podem dialogar sobre os mesmos com propriedade.

Segue uma síntese das respostas aos itens dirigidos aos coordenadores de GDP.

a) Expectativa de participar de um Programa de Desenvolvimento Profissional.

Para os respondentes, o Programa de Desenvolvimento Profissional se torna um dispositivo de apoio às escolas e aos próprios profissionais a fim de aprimorar a maneira de trabalhar os conteúdos e de melhorar o funcionamento da escola. Isto é sinalizado pelo modo como os professores acolheram a proposta. As expectativas iniciais apontaram para a forma como encararam o projeto na formação continuada de cada um deles, o que fica evidenciado por: "As escolas não vivenciavam nenhuma evolução"; "é um apoio ao educador"; "hoje (com o PDP) utilizamos outros meios, melhores que os de antigamente”. A opinião dos respondentes confirma o argumento de Nóvoa (1997) de que é indispensável conjugar a necessidade dos professores e das escolas com a oferta de formação definida em ligação estreita com o desenvolvimento curricular e a organização da escola. Indica que jamais a formação deva ser indissociável dos projetos organizacionais e profissionais.

Outro ponto relevante é a segurança que o professor passa a ter para empreender um novo projeto educacional. Sentir-se apoiado em sua trajetória pode não representar, para o professor, um fracasso ao abraçar uma proposta nova.

b) Considerações sobre o Programa de Desenvolvimento Profissional. 


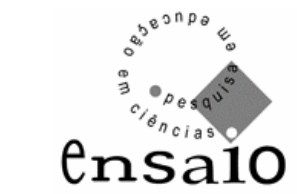

Vol. 11 no 1 junho 2009

Em relação a esse item, as respostas dos depoentes expressam características do objetivo do programa citadas anteriormente: “o meu grupo sentiu logo no início que seria necessário um trabalho cooperativo... pois a liberdade dada à escola é positiva, mas exige preparo e muito trabalho"; “troca de experiência, ajudamos a elaborar esse projeto, ouvir o professor, grande avanço na democracia da educação”. O sentido de organização curricular em conteúdos mínimos, com alternativas de abordagem metodológica, chamou a atenção de um respondente: “cada professor por disciplina adotava o seu currículo; ... hoje, todas as escolas têm o compromisso de adotar um único currículo”. No entanto, o ponto que mais destacam é a troca de experiência.

c) Fatores que dificultam e favorecem a implantação do PDP.

Quanto ao primeiro item, os professores reforçaram velhos problemas: “ $O$ que impede é a rotatividade dos profissionais na Escola, uma grande maioria não participa e às vezes dificulta o trabalho daquele que está comprometido com a proposta”. Ou: “A estrutura é um grande impedimento do PDP, tudo depende de uma autorização”. Acrescentam que o cronograma é apertado, que falta disponibilidade de tempo, e que a avaliação não é condizente com a flexibilização curricular que o programa propõe.

Por outro lado, os respondentes constituem um grupo que vê que as transformações estão sendo positivas: “este projeto me fez mudar posturas e metodologias que usava em minhas aulas. O que favorece é a necessidade de mudar"; "houve benefícios, principalmente na mudança de atitudes dos educadores"; "tudo isso ficou mais prazeroso". Há uma confiança de que a credibilidade no programa para mudar a realidade educacional venha a ser conquistada aos poucos embora, como dizem, encontrem dificuldades.

Na opinião de Lelis (2003, p. 88), “o alerta a ser feito refere-se ao perigo de cairmos no corporativismo que tende a ser perverso e autoritário ao levar à divisão de interesses e necessidades de determinados grupos e setores, esvaziando a vontade geral, os desejos e motivações da maioria”, obscurecendo a do conjunto da problemática educacional.

d) O desenvolvimento das reuniões de GDP. 


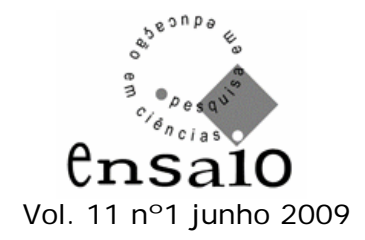

Identificamos que os encontros, mediados pelo coletivo, realizados em cada escola, propiciaram uma prática interativa, dialógica e reflexiva inquestionável, favorável à concretização do Projeto, na medida em que se tornam momentos oportunos para o professor expor, aos demais membros do grupo, seu pensamento, sua crítica e manifestar sua maneira de ser e seu modo de desempenhar a profissão. É o que expressa os depoimentos: “houve troca de experiência, clima harmônico e agradável, momentos de reflexão sobre as ações realizadas, para o replanejamento"; "é uma democracia, o professor está comprometido, momentos em que temos que extravasar”; "(no início) todos os professores do grupo vinham e ficavam questionando porque estavam ali e que não estavam ganhando nada com isso. Mas esse ano é que eles estão vendo os frutos que estão colhendo”.

Para Imbernón (2006), a formação deve se converter em "um processo de autodeterminação baseado no diálogo, à medida que se implanta um tipo de compreensão compartilhada pelos participantes, sobre as tarefas profissionais e os meios para melhorá-las, e não, de papéis e funções que são aprimorados mediante normas e regras técnicas”. (p. 82)

e) Avaliação do PDP e do CBC.

Pelos depoimentos a seguir, percebemos que a formação é condição de mudança e, ao incluir dimensões coletivas de trabalho no processo de pensar e fazer, permite aos professores intervir com mais eficácia no contexto educacional, decidindo sobre objetivos, práticas e sobre a organização escolar: " $O P D P$ possibilita a cada profissional melhorar sua qualificação"; "O Programa de Desenvolvimento Profissional é um meio de fazer com que o professor estude, me faz refletir, porque você muda a prática pedagógica, nós temos contatos por email e trocamos experiências, é crescimento pessoal e não tem dinheiro que pague. O Currículo Básico Comum dá uma uniformidade”; "O CBC tem um caráter inclusivo, permite acesso ao mesmo nível acadêmico, eliminando particularidade de regiões e de outras diversidades”; “O PDP não terminou ainda, mas pelo menos as mudanças que nós tivemos e a união de todos, tudo isso valeu. O CBC está tranqüilo”. 


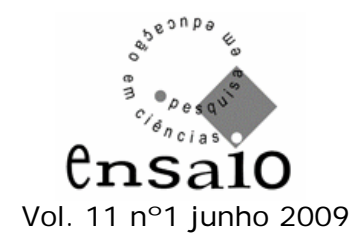

Para eles, a autêntica formação não é mera instrumentalização de um Currículo Básico Comum. Em consonância com o relato dos professores, o processo de pensar e fazer não deve se limitar à sala de aula. $\mathrm{O}$ pensar e o fazer devem ultrapassar os limites de cada dimensão coletiva de trabalho. Para Ghedin (2002), os professores devem considerar, nessa ação coletiva, “o sentido político, cultural e econômico que cumpre à escola; como esse sentido condiciona a forma em que ocorrem as coisas no ensino, como se tem interiorizado os padrões ideológicos sobre os quais se sustenta a estrutura educativa” (p. 137).

Em relação ao $\mathrm{CBC}$, os professores respondentes estão seguros quanto às alterações propostas. No entanto, devem procurar caminhos no sentido do desenvolvimento de uma mentalidade curricular que permita a eles lidar com a diversidade de interesses e situações regionais e, ao mesmo tempo, devem ser coautores na configuração do currículo. Para isso se faz necessário romper com “a separação entre os conceptores (os administrativos da tutela educativa e os acadêmicos) e os práticos (os professores das escolas)” separação essa criticada por Leite (2005, p. 128), ou seja, com a tradição da existência dos que prescrevem e dos que cumprem o que é prescrito. Sabemos que, entre a incorporação de um discurso e a efetivação das ações, há um caminho a ser construído e barreiras a serem desconstruídas, num processo que não se limita a um ou dois anos somente. f) Avaliação dos recursos de apoio disponibilizados pela Secretaria de Estado de Educação de Minas Gerais.

Dos quatro respondentes, apenas um tem restrição quanto aos recursos que a escola recebe: “Os recursos disponibilizados ainda deixam a desejar. Precisa avançar mais". Outro, no entanto, conta com o apoio que o projeto oferece: “Ainda falta bastante, mas nós temos um (0800) zero oitocentos que a gente liga e esclarece dúvidas. Nós temos o contato com os nossos orientadores em Belo Horizonte, por e-mail ou telefone. Está sendo investido em rede física, quem quer faz”. Os demais consideram que os recursos atenderam às suas expectativas: " $a$ SEEMG tem nos dado o apoio prometido"; "Não temos que dizer que não veio recurso". 


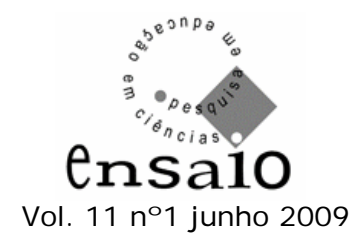

Esse recurso vem sendo utilizado como sendo uma das novas formas de comunicação para melhorar as relações institucionais. As políticas educacionais incorporaram essa tecnologia aos processos pedagógicos. Consideramos que "as Tecnologias de Informação e de Comunicação - TIC - abrem novas possibilidades para a educação e devem promover o enriquecimento da formação e do trabalho docente.” (BARRETO, 2005, p. 145). No entanto, os professores devem analisar como as Tecnologias de Informação e Comunicação têm sido impostas pelas políticas educacionais.

g) Experiência marcante no projeto.

Percebe-se, na fala de três coordenadores, que o que se tornou mais significativo nesse processo de desenvolvimento profissional foi encontrar parceiros nessa luta. Os depoimentos "Meu grupo de estudo levou a sério" e "O curso em Belo Horizonte foi uma experiência pessoal marcante dentro do processo do $P D P$ ” revelam que não se sentiram sozinhos ao terem de enfrentar obstáculos na busca de uma nova prática pedagógica. Encontraram pessoas para, com eles, compartilharem as idéias e conhecimentos. É possível constatar que atribuem valor à dinâmica relacional na formação. Para Estrela (2002, p. 161), “a formação em pequenos grupos quebra o isolamento do trabalho docente, permite troca de experiências e perspectivas (...)”.

Garcia, citando Rudduck, realça essa concepção de desenvolvimento profissional:

[ela] pressupõe uma valorização dos aspectos contextuais organizativos e orientados para a mudança. Essa perspectiva constitui um marco decisivo para a resolução de problemas escolares no sentido da superação do caráter tradicionalmente individualista das atividades de aperfeiçoamento dos professores. (1997, p. 55)

\section{CONSIDERAÇÕES GERAIS}

Na experiência de Minas Gerais, a estratégia de desenvolvimento profissional implantada foi planejada e orientada por especialistas; seria, no 


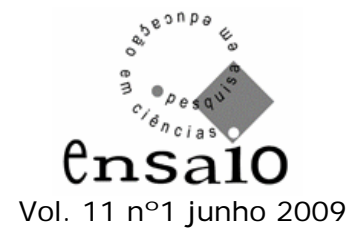

entanto, primordial a participação dos professores na etapa de planejamento da proposta. É necessário concordar com Feldfeber e Imen (2006):

As propostas de profissionalização sustentadas no contexto da reforma omitem toda referência ao exercício do poder que compreende a profissão docente, ao mesmo tempo em que se promovem dispositivos que desqualificam a tarefa docente e lhe tiram crescentes cotas de poder com relação a definições centrais dessa tarefa. (p. 170)

A proposta da SEEMG, em relação ao Projeto Escolas-Referência e ao Programa de Desenvolvimento Profissional contido nele, corresponde às orientações do Banco Mundial, financiador do projeto. Dada a abrangência das orientações, poderá a escola se tornar inovadora e ser pensada no contexto da realidade sócio-etno-cultural em que se encontra? Poder-se-á obter excelência na educação sendo orientada por políticas de agências internacionais?

É importante, no entanto, ressaltar a quebra de resistência dos professores à mudança na busca de ações alternativas, através da reflexão sobre a prática pedagógica, da autocrítica de sua atuação, do senso de responsabilidade correspondendo ao empenho dedicado à própria formação e ao estudo do novo plano curricular no sentido de implementá-lo e, igualmente, através do esforço para a viabilização do CBC.

A formação continuada pretendida nesse programa é uma importante decisão da SEEMG para as mudanças organizacionais da escola convertendo os professores em co-partícipes. Espaços educacionais foram criados implicando uma participação coletiva, reflexiva e crítica nesse processo de formação, e possibilitaram a articulação entre o agir, o pensar, o saber e o poder sobre cada tema posto em discussão pelos coordenadores e os seus grupos de GDP. Concordamos com a posição de Anastasiou (2004, p.60): “Pensar a disciplina isoladamente, como preocupação pessoal e individual, faz parte de nossa história profissional. Pensá-la coletivamente conduz a outro tipo de trabalho, mesmo porque 


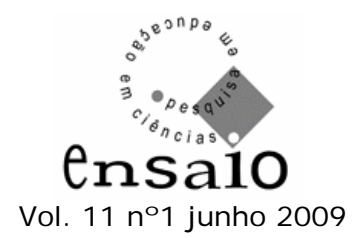

exigirá que se inicie um novo processo na profissão”. Pode-se imaginar que este é um primeiro passo para pensar a escola em termos mais globais.

Uma característica que precisa ser reconhecida como positiva nessa política de capacitação é o fato de ser uma proposta emancipadora e pedagogicamente progressista para a educação ao buscar a superação de práticas tradicionais ineficientes. Ao implantar o CBC, questionamentos, novas concepções e teorias emergiram constituindo-se como elementos essenciais à mudança da concepção e da prática tradicionais.

Assim, cinco aspectos merecem destaque na estratégia desse modelo de formação continuada, proposto pela SEEMG, mesmo estando ainda em fase experimental de implantação: ter como locus a própria escola; apoiar-se na gestão de redes de conhecimento para o empreendimento da mudança das práticas profissionais; contar com a participação dos professores com base em novas perspectivas, novos enfoques e novas estratégias de trabalho; possibilitar a promoção de visão partilhada, aprendizagem em equipe; empreender estudos e esforços na utilização de novas aprendizagens como meio para o desenvolvimento e aprimoramento do trabalho pedagógico e do próprio desenvolvimento profissional.

No entanto, deve-se registrar o grande número de professores que ainda não estão integrados nessa política governamental de formação continuada. Diante desse fato, temos de admitir o reduzido impacto dessa nova cultura de profissionalização dos docentes para que se concretize a almejada transformação da realidade educacional mineira, tendo em vista os desafios da educação tais como a qualidade de ensino, a permanência das crianças e adolescentes, com efetiva aprendizagem, na escola e o desenvolvimento profissional de professores.

Aos olhos de quem vivenciou o processo, o programa torna-se ineficaz: se os recursos materiais e os recursos metodológicos forem insuficientes, se as classes continuarem numerosas, se as condições físicas das escolas não oferecerem condições adequadas ao desenvolvimento do ensino, se os professores não forem chamados a participar da elaboração das propostas curriculares, se persistir a rotatividade dos professores, se os professores não tiverem adequadas condições de trabalho e salário. 


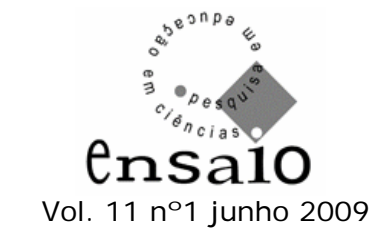

O professor deverá permanentemente enfrentar os desafios, as situações adversas vivenciadas nesse processo formativo incorporando à sua formação o diálogo, a reflexão, a crítica e um profundo embasamento teórico para a definição de ações na condução do processo educativo.

\section{REFERÊNCIAS BIBLIOGRÁFICAS}

ALTMANN, Helena. Influências do Banco Mundial no projeto educacional brasileiro. In: Educação e Pesquisa, v.28, n.1, São Paulo jan/jun. 2002, p.1-9. Disponível em http://www.scielo.br/scielo.php?script=sci_arttext\&pid. Acessado em 10/10/2006

ANASTASIOU, L. G. C. Da visão de Ciência à Organização Curricular. In: ANASTASIOU, L. G. C.; ALVES, L. P. Processos de Ensinagem na Universidade: pressupostos para as estratégias de trabalho em aula. Joinville, SC: Editora UNIVILLE, 2004, p.39-65.

APPLE, M. W. Política, cultura e educação. São Paulo: Cortez, 2000.

BARRETO, R. G. A presença das tecnologias. In: FERRAÇO, C. E. (Org.). Cotidiano escolar, formação de professores (as) e currículo. São Paulo: Cortez, 2005.

CANDAU, V. M. Magistério: construção cotidiana. Petrópolis, RJ: Vozes, 2003.

CORAGGIO, J. L. Propostas do Banco Mundial para a educação: sentido oculto ou problemas de concepção? In: TOMMASI, L. de; WARDE M. J.; HADDAD, S. (Orgs.). O banco mundial e as políticas públicas educacionais. São Paulo, Cortez, 1996.

ESTRELA, M. T. A investigação como estratégia de formação contínua de professores: reflexão sobre uma experiência. In: NETO, A. S. e MACIEL, L. S. B. (Orgs.). Reflexões sobre a formação de professores. Campinas, SP: Papirus, 2002.

FELDFEBER, M. e IMEN, P. A formação continuada dos docentes: os imperativos da profissionalização em contexto de reforma educativa. In: FERREIRA, N. S. C. (Org.). Formação continuada e gestão da educação. São Paulo: Cortez, 2006.

FUSARI, J. C. e RIOS, T. A. Formação continuada dos profissionais do ensino. CEDES. Educação continuada. n.36, 1995. p.37-44. 


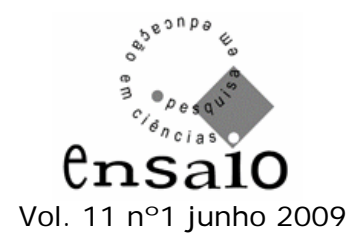

GARCIA, C. M. A formação de professores: novas perspectivas baseadas na investigação sobre o pensamento do professor. In: NÓVOA, A. (Org.). Os professores e a sua formação. Lisboa, Dom Quixote, 1997.

GHEDIN, E. Professor reflexivo: da alienação da técnica à autonomia da crítica. In: PIMENTA, S. G., GHEDIN, E. Professor reflexivo no Brasil: gênese e crítica de um conceito. São Paulo: Cortez, 2002.

IMBERNÓN, F. Formação docente e profissional: formar-se para a mudança e a incerteza. São Paulo: Cortez, 2006.

LEITE, C. O currículo e o exercício profissional docente face aos desafios sociais desta transição de século. In: FERRAÇO, C. E. (Org.). Cotidiano escolar, formação de professores (as) e currículo. São Paulo: Cortez, 2005.

LELIS, I. A. A prática do educador: compromisso e prazer. In: CANDAU, V. M. (Org.). Magistério: construção cotidiana. Petrópolis, RJ: Vozes, 2003.

LIMA, M. E. C. de C. Formação Continuada de Professores. In: Diretrizes Curriculares da Escola Sagarana - Guia de Estudo 5. Minas Gerais: Governo do Estado de Minas Gerais, 2001.

MERCADO, L. P. L. Formação continuada de professores e novas tecnologias. Maceió, RE: Edufal, 1999.

MINAS GERAIS. Secretaria de Estado Educação. Resolução $\mathbf{N}^{\mathbf{0}} \mathbf{7 5 3}$ de 06 de janeiro de 2006.

MINAS GERAIS. Secretaria de Estado de Educação. Proposta Curricular: Educação Básica. Cadernos Pedagógicos, Belo Horizonte, 2005.

MINAS GERAIS. Secretaria de Estado de Educação. Resolução N $^{\mathbf{0}} \mathbf{6 6 6}$ de 07 de abril de 2005.

MINAS GERAIS. Secretaria de Estado de Educação. Projeto de Desenvolvimento Profissional de Educadores - PDP: Manual de Orientação. Belo Horizonte, 2004.

MINAS GERAIS. Secretaria de Estado de Educação. Projeto de Desenvolvimento Profissional de Educadores - PDP: Manual do Coordenador. Belo Horizonte, 2004.

MINAS GERAIS. Secretaria de Estado de Educação. Projeto de Desenvolvimento Profissional de Educadores - PDP: Roteiro de Estudos das Propostas e Orientações Curriculares. Belo Horizonte, 2004. 


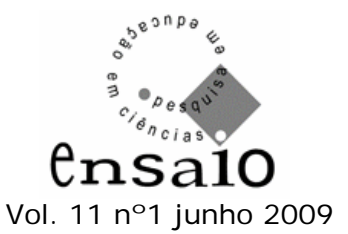

MINAS GERAIS. Secretaria de Estado de Educação. Centro de Referência Virtual. Disponível em: http://crv.educacao. mg.gov.br. Acesso em 14/10/2005.

MINAS GERAIS. Secretaria de Estado de Educação. Projeto Escolas - Referência: A reconstrução da excelência na escola pública. Belo Horizonte, 2004.

MIZUKAMI, M. da G. N., et al. Escola e aprendizagem da docência: processos de investigação e formação. São Carlos, SP: EdUFISCar, 2002.

NÓVOA, A. Formação de professores e profissão docente. In: NÓVOA, A. (Org.). Os professores e a sua formação. Lisboa, Dom Quixote, 1997.

PACHECO, J. A., MORAES, M. C. e EVANGELISTA, O. Políticas educacionais nos anos 90: a formação de professores no Brasil e em Portugal. Educar em Revista. n.18, p. 185-199, jul. 2001.

TOMMASI, L. Financiamentos do Banco Mundial no setor educacional brasileiro: os projetos em fase de implementação. In TOMMASI, L.; WARDE M. J.; HADDAD, S. (Orgs.). O banco mundial e as políticas públicas educacionais. São Paulo, SP: Cortez, 1996.

TORRES, R. M. Melhorar a qualidade da educação básica? As estratégias do Banco Mundial e as políticas educacionais. In TOMMASI, L.; WARDE M. J.; HADDAD, S. (Orgs.). O banco mundial e as políticas públicas educacionais. São Paulo: Cortez, 1996.

Data de recebimento: 17/04/07

Data de aprovação: 08/08/08

Data de versão final: 17/11/08 